\title{
Functional esophageal disorders
}

\author{
R E Clouse, J E Richter, R C Heading, J Janssens, J A Wilson
}

Chair, Committee on Functional Esophageal Disorders,

Multinational Working

Teams to Develop

Diagnostic Criteria for

Functional

Gastrointestinal

Disorders (Rome II),

Washington University,

St Louis, MO, USA

R E Clouse

Co-Chair, Committee on Functional

Esophageal Disorders, Multinational Working Teams to Develop

Diagnostic Criteria for Functional

Gastrointestinal

Disorders (Rome II),

The Cleveland Clinic,

Cleveland, Ohio USA

J E Richter

University of

Edinburgh

Edinburgh, Scotland,

UK

R C Heading

University of Leuven, Leuven, Belgium

J Janssens

Freeman Hospital, Department of

Surgery,

Newcastle-upon-Tyne, UK

J A Wilson

Correspondence to: Ray E Clouse, MD, Barnes-Jewish Hospital, North Campus, 216 South Kingshighway Boulevard, Suite 6330, St Louis, MO 63110-1092, USA. Email: rclouse@im.wustl.edu

\begin{abstract}
The functional esophageal disorders include globus, rumination syndrome, and symptoms that typify esophageal diseases (chest pain, heartburn, and dysphagia). Factors responsible for symptom production are poorly understood. The criteria for diagnosis rest not only on compatible symptoms but also on exclusion of structural and metabolic disorders that might mimic the functional disorders. Additionally, a functional diagnosis is precluded by the presence of a pathology-based motor disorder or pathological reflux, defined by evidence of reflux esophagitis or abnormal acid exposure time during ambulatory esophageal pH monitoring. Management is largely empirical, although efficacy of psychopharmacological agents and psychological or behavioral approaches has been established for serveral of the functional esophageal disorders. As gastroesophageal reflux disease overlaps in presentation with most of these disorders and because symptoms are at least partially provoked by acid reflux events in many patients, antireflux therapy also plays an important role both in diagnosis and management. Further understanding of the fundamental mechanisms responsible for symptoms is a priority for future research efforts, as is the consideration of treatment outcome in a broader sense than reduction in esophageal symptoms alone. Likewise, the value of inclusive rather than restrictive diagnostic criteria that encompass other gastrointestinal and non-gastrointestinal symptoms should be examined to improve the accuracy of symptom-based criteria and reduce the dependence on objective testing.

(Gut 1999;45(Suppl II):II31-II36)
\end{abstract}

Keywords: globus; rumination; chest pain; esophageal motility disorders; esophageal spasm; gastroesophageal reflux disease; Rome II

Functional esophageal disorders represent chronic symptoms that typify esophageal disease yet have no identifiable structural or metabolic basis (table 1). Mechanisms responsible for the symptoms are poorly understood, but a combination of physiologic and psychosocial factors probably is responsible for escalating symptoms to a level requiring medical attention. Several diagnostic requirements are uniform across the functional esophageal disorders. Firstly, the exclusion of structural or metabolic disorders that might be producing the symptoms. ${ }^{1}$ Secondly, the presence of at
Table 1 Functional gastrointestinal disorders

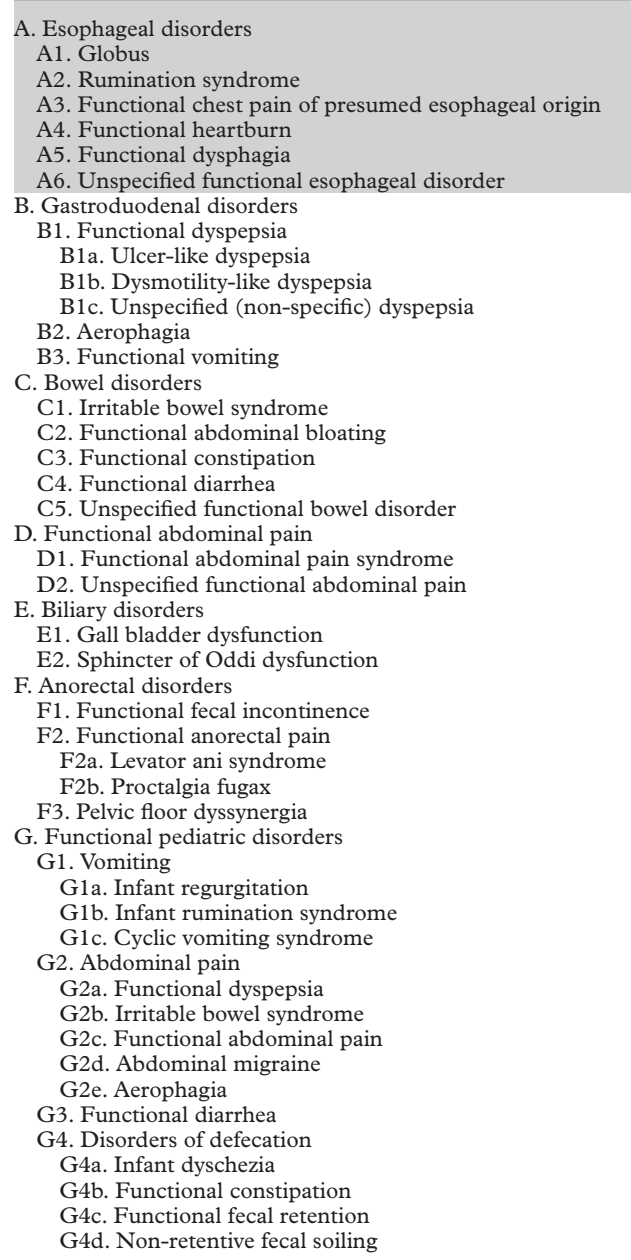

least three months of symptoms, counted as 12 weeks in the preceding year, an arbitrary criterion in the case of the functional esophageal disorders. Thirdly, the exclusion of pathologic reflux or a pathology-based motor disorder as the primary cause of symptoms. Pathologic reflux is defined as evidence of esophagitis or abnormal esophageal acid exposure during ambulatory 24-hour pH monitoring. Symptoms associated with reflux events, no matter how closely linked, will still qualify toward a functional diagnosis in the absence of pathologic reflux.

\section{A1. Globus}

DEFINITION

Globus is a sensation of a lump, something stuck, or tightness in the throat. Classically, a lump, it may be a hair- or crumb-like (foreign body) sensation, a constriction or a choking. The symptom is considered functional when no organic explanation is detected. Many 
physical diseases are blamed for the symptom, including sinusitis, tonsillitis, cervical spondylitis, and other otolaryngological explanations, but a true association of the symptom with these disorders is not well established.

\section{EPIDEMIOLOGY}

Nearly half of the general population has intermittent symptoms resembling globus. ${ }^{2}$ More severe and distressing symptoms represent up to $4 \%$ of referrals to otolaryngological specialists. Peak incidence is in middle age, and three of four subjects seeking health care for globus are women. Nevertheless, the everyday experience of the symptom is reported similarly by both sexes. ${ }^{2}$

DIAGNOSTIC CRITERIA

At least 12 weeks, which need not be consecutive, in the preceding 12 months of:

(1) The persistent or intermittent sensation of a lump or foreign body in the throat;

(2) Occurrence of the sensation between meals;

(3) Absence of dysphagia and odynophagia; and

(4) Absence of pathologic gastroesophageal reflux, achalasia, or other motility disorder with a recognized pathologic basis such as scleroderma of the esophagus.

JUSTIFICATION FOR CHANGE TO CRITERIA

The sensation of globus most often occurs centrally in the neck, but may migrate in location and is reported in a lateral position in $20 \%$ of patients. ${ }^{3}$ Therefore, the prior restrictions on location were removed.

\section{CLINICAL EVALUATION}

Clinical evaluation centers around a history that tackles psychosocial factors and a thorough examination of the neck, larynx, and pharynx. Sensations localized above the cricoid arise in areas visible by flexible laryngoscopy. Direct (rigid) laryngoscopy has a role in investigation of some patients, especially those with associated symptoms that might suggest malignancies. Barium radiographs have a limited role for detecting pharyngeal abnormalities but may help discover a distal esophageal motor disorder or reflux esophagitis. Patients with these latter findings are likely to have symptoms of reflux disease or dysphagia along with globus.

\section{PHYSIOLOGIC FEATURES}

A physiologic explanation for this symptom in the average patient remains obscure. The interprandial dry swallow frequency increases as subjects try to "dislodge" the foreign body. Paradoxically, this dry swallow habit has been postulated as an indirect cause of the symptom, perhaps by building up a column of air periodically trapped beneath the upper esophageal sphincter. ${ }^{4}$ A dependable abnormality in upper esophageal sphincter function has not been detected. Overt gastroesophageal reflux disease is found in more than a quarter of patients presenting with globus-like symptoms. ${ }^{5}$ Once these subjects are excluded from further consideration, the role of gastroesophageal reflux is limited and inconsistent. Achalasia and other distal esophageal motor disorders can produce globus, but most motor abnormalities found in patients with globus are non-specific with obscure physiologic importance. ${ }^{6}$

\section{PSYCHOLOGIC FEATURES}

Psychologic abnormalities are detected inconsistently in patients with globus. Anxiety and affective symptoms are common in these patients. Personality abnormalities, particularly low extraversion levels, have been found in women. Recent studies of personality suggest that alexithymia, a difficulty in expressing emotional feelings, may be relevant. ${ }^{7}$ Causal relationships between emotional abnormalities and globus have not been established, although patients with globus report a greater number of severe life events than controls over the year preceding symptom onset.

\section{TREATMENT}

Reassurance is a standard but unproved mainstay. Antireflux therapy will potentially help the subset with reflux disease that was overlooked during evaluation. Because of the inconsistent relationship of reflux to globus in the remainder, treatment should be discontinued if initially ineffective. In the absence of major esophageal motor disturbance (e.g., achalasia), treatment directed at motor dysfunction is not of established benefit. Psychopharmacologic and psychotherapeutic approaches have been understudied in globus, but the long term course is not clearly related to comorbid psychiatric disorders. ${ }^{8}$ Anecdotal reports favor use of anxiolytics and antidepressants, but patient dropout was high in a small controlled trial of tricyclic antidepressants for this disorder. ${ }^{9}$

\section{A2. Rumination syndrome}

DEFINITION

Rumination syndrome is defined, in the absence of structural disease, as a regurgitation of recently ingested food into the mouth with subsequent remastication and reswallowing or spitting out. The symptom is effortless, not associated with abdominal discomfort, heartburn, or nausea, and can suggest a voluntary pleasurable experience. Symptoms occur in the postprandial period and cease when the food taste becomes acidic.

\section{EPIDEMIOLOGY}

Rumination syndrome is male dominant (2:1) and encountered most commonly in infancy and in mentally handicapped children and adults. ${ }^{10}$ Few adults of normal intelligence seek medical attention for rumination, and physician awareness is poor. ${ }^{11}$ Rumination accounts for up to $0.07 \%$ of admissions to children's hospitals and occurs in $6-10 \%$ of institutionalized, mentally handicapped children. The majority of information about this 
disorder and its management comes from these subsets.

DIAGNOSTIC CRITERIA

At least 12 weeks, which need not be consecutive, in the preceding 12 months of:

(1) Persistent or recurrent regurgitation of recently ingested food into the mouth with subsequent remastication and swallowing;

(2) Absence of nausea and vomiting;

(3) Cessation of the process when the regurgitated material becomes acidic; and

(4) Absence of pathologic gastroesophageal reflux, achalasia, or other motility disorder with a recognized pathologic basis as the primary disorder.

CLINICAL EVALUATION

The diagnosis is established by typical symptoms and the absence of organic esophageal or gastric diseases. In patients without previous evaluation, gastroesophageal reflux, gastric outlet obstruction, other mechanical disorders responsible for delayed gastric emptying, and significant gastric or esophageal motility disorders must be considered. Conditions typically confused with rumination syndrome include gastroesophageal reflux disease and bulimia. Diagnostic studies are aimed at excluding confounding disorders and may include videoesophagography, upper gastrointestinal radiography, endoscopy, and, on occasion, esophageal or gastrointestinal motility studies.

\section{PHYSIOLOGIC FEATURES}

Rumination can be initiated by a belch or swallow whereby lowered lower esophageal sphincter pressure creates a common cavity between the stomach and the esophagus. This process is occasionally initiated by digital or lingual stimulation of the palate and pharynx. Dysmotility within the body of the esophagus is not a part of the process. Some subjects show a characteristic pressure spike wave motor pattern measured simultaneously along the gastric antrum and proximal duodenum with sudden decreases in intraesophageal $\mathrm{pH}^{12}{ }^{13}$ Others demonstrate notably reduced compliance of the proximal stomach.

PSYCHOLOGIC FEATURES

Central factors contribute significantly to the occurrence of rumination, and mechanistic theories have been developed. In mentally handicapped individuals, the degree of neuropsychiatric impairment largely determines the importance of the symptom. In normally developed children, rumination may represent a self-stimulating positive behavior resulting from a poor mother-infant relationship. ${ }^{14}$ Alternatively, the behavior may be learned as a conditioned response maintained by the reward of increased parental attention or the positive feedback associated with the taste of regurgitated food. Whether these apply to intellectually intact adults is not clear. Rumination may be a learned habit that has persisted from childhood with parental approval. An association with specific psychiatric disorders is not established.

TREATMENT

Treatment depends on the age of the patient and the presence of underlying mental deficit. In children, punishment techniques (aimed at stopping habitual behavior) and increased holding or increased mothering by a surrogate (aimed at improving emotional bonding between mother and infant) have both been effective. A range of medical, behavioral, and nutritional approaches have been attempted in patients with mental handicaps with varied success. ${ }^{15}$ Non-adversive behavioral therapies have been most effective in adults with normal intelligence. $^{16}$

\section{A3. Functional chest pain of presumed esophageal origin}

DEFINITION

This functional disorder is characterized by episodes of chest pain that are usually midline, of visceral quality, and therefore, potentially of esophageal origin. Because the symptoms can be confused with cardiac pain, exclusion of cardiac disorders is necessary.

\section{EPIDEMIOLOGY}

Prevalence is uncertain. Extricating patients with functional chest pain from those with ischemic heart disease is difficult, especially in the older population. Up to $15-30 \%$ of coronary arteriograms performed for chest pain evaluation are within normal limits, supporting a high prevalence. Patients with functional chest pain of presumed esophageal origin have a favorable prognosis-for example, death from cardiac causes is $<1 \%$ over seven years of follow up in patients with chest pain with an initially negative cardiac evaluation. ${ }^{17}$

DIAGNOSTIC CRITERIA

At least 12 weeks, which need not be consecutive, in the preceding 12 months of:

(1) Midline chest pain or discomfort that is not of burning quality; and

(2) Absence of pathologic gastroesophageal reflux, achalasia, or other motility disorder with a recognized pathologic basis.

JUSTIFICATION FOR CHANGE TO CRITERIA

To avoid overlap with criteria for functional heartburn, pain or discomfort with burning quality is excluded in the revised criteria.

\section{CLINICAL EVALUATION}

Initial diagnostic studies should eliminate cardiothoracic causes of pain. Identifying the presence of gastroesophageal reflux disease and its relationship to pain episodes is important. Esophagitis, inferential evidence of refluxrelated pain, can be found in up to $30 \%$ of patients with otherwise unexplained chest pain, although detection rates have not been this high in all studies. ${ }^{18}$ Further evidence of pathologic reflux may be detected using ambulatory 24-hour $\mathrm{pH}$ monitoring; antireflux therapy 
may eliminate this group of patients from further consideration. Establishing a relationship between chest pain and reflux events, even in the absence of pathologic reflux, is helpful in identifying additional potential responders to antireflux treatment. Clinical response to a short course of high-dose proton pump inhibitor therapy before investigation is a cost effective method of determining the value of antireflux therapy for many patients. ${ }^{19}$ Esophageal motility testing has a limited role in studying patients who do not have other symptoms of esophageal dysfunction, especially dysphagia.

PHYSIOLOGIC FEATURES

Physiologic abnormalities are found inconsistently in patients with functional chest pain, may be uncovered during the clinical evaluation, but are not required for diagnosis. Up to $15 \%$ of patients will show a close association of chest pain episodes to acid reflux events, even in the face of normal 24-hour esophageal acid exposure times. ${ }^{20}$ Such patients seem to be hypersensitive to physiologic quantities of acid reflux. Half or more have abnormal distal esophageal motility, particularly non-specific spastic disorders. ${ }^{21}$ These findings are poorly correlated with episodes of chest pain in the majority of patients. Provocation maneuvers with intravenous edrophonium chloride or balloon distension reproduce chest pain in up to $50 \%$ of patients. ${ }^{22}{ }^{23}$ Physiologic abnormalities, although prevalent in these patients, presently have limited impact on the treatment approach.

PSYCHOLOGIC FEATURES

A history of psychiatric disorder is found in more than $60 \%$ of patients, a rate at least double that in appropriately symptomatic controls. ${ }^{24}$ Anxiety disorders, depression, and somatization disorder are the most common diagnoses. Presence of psychiatric disorder is independent of physiologic abnormalities. Outcome in patients with chest pain is correlated with the degree of psychosocial morbidity. Sensory decision theory methods, experimental tasks that determine reasons for reporting symptoms, show that patients with functional chest pain have lower pain thresholds and set lower standards for judging esophageal distension stimuli as painful. ${ }^{25}$ Psychological factors may contribute to these findings, including use of negative pain coping strategies, poor implementation of specific pain-reducing behaviors, and reinforcement of pain behavior by spouses or significant others.

TREATMENT

Once significant structural disease (including cardiac disease) is excluded, reassurance plays an important role in management. An aggressive trial of acid suppression for at least one to two months is recommended initially, and more than $75 \%$ of patients unselected by presence or absence of documented reflux disease will respond to high-dose acid suppression in the first week. ${ }^{19}{ }^{26}$ Medications directed at nonspecific motility disorders, including nitrates, anticholinergics, and calcium-channel block- ers, have been popular, but controlled trials assessing their benefit are inconclusive. Two double-blind, placebo-controlled studies support the use of low-dose antidepressant therapy. ${ }^{27}{ }^{28}$ Outcome is not related to the presence of physiologic abnormalities at presentation (e.g., esophageal motility abnormalities, balloon distension sensitivity), nor is improvement dependent on changes in these parameters. Psychological management can improve outcome in terms of chest pain episodes, functional disability, and psychological distress. ${ }^{29}$ Some of the longest follow up data available for evaluating outcome come from psychological treatment. ${ }^{29}$

\section{A4. Functional heartburn}

DEFINITION

Functional heartburn is defined as episodic retrosternal burning in the absence of pathologic gastroesophageal reflux, pathology-based motility disorders, or structural explanations. The term can still be applied to those patients whose symptoms are associated with acid reflux events during ambulatory $\mathrm{pH}$ monitoring, provided that the duration of esophageal acid exposure is normal.

EPIDEMIOLOGY

Up to $30 \%$ of Western populations report heartburn, but the distribution of pathologic versus functional disorders is not known. ${ }^{230}$ Few patients seek medical care for diagnosis. Functional heartburn is diagnosed in a minority of subjects seeking care from gastroenterologists for presumed gastroesophageal reflux disease.

DIAGNOSTIC CRITERIA

At least 12 weeks, which need not be consecutive, in the preceding 12 months of:

(1) Burning retrosternal discomfort or pain; and

(2) Absence of pathologic gastroesophageal reflux, achalasia, or other motility disorder with a recognized pathologic basis.

JUSTIFICATION FOR CHANGE TO CRITERIA

Evidence-based data to determine specific symptom features of functional heartburn, including diurnal characteristics, exacerbating factors, and ameliorating maneuvers, are absent. The criteria were revised to acknowledge this lack of information and to include all subjects with heartburn unexplained by pathologic conditions until further scientific data are available.

CLINICAL EVALUATION

Clarification of the nature of the symptom is an essential first step. Other characteristics of gastroesophageal reflux disease should be identified to focus the investigation on the esophagus. Heartburn may accompany other esophageal (e.g., achalasia) and nonesophageal disorders (e.g., coronary artery disease), the degree of investigation largely being determined by clinical suspicion. Little is required in the way of formal diagnostic 
workup for patients with brief, intermittent, or episodic symptoms that are responsive to overthe-counter treatment. The investigation is straightforward for patients with longer-lasting symptoms, troublesome symptoms, or poor response to medication.

PHYSIOLOGIC FEATURES

A degree of hypersensitivity to intraluminal stimuli has been proposed for this disorder. Despite a lack of pathologic reflux, patients with functional heartburn may demonstrate a good temporal association between symptoms and acid exposure; at least a third of heartburn episodes are preceded by acid reflux events. ${ }^{31}$ Those with heartburn with normal esophageal acid exposure times also have lower thresholds to intraesophageal balloon distension. ${ }^{32}$ Heartburn and reflux events are also partially related in some patients with functional dyspepsia, another disorder wherein visceral hypersensitivity has a presumed pathogenic role.

\section{PSYCHOLOGIC FEATURES}

Psychologic features in patients with functional heartburn have been poorly characterized. Heartburn not correlated with acid reflux events on $\mathrm{pH}$ monitoring predicts heightened anxiety, emotional lability, and poor social support compared with correlated symptoms. ${ }^{33}$ In contrast, illness behavior has not differentiated patients with functional heartburn from others with bona fide reflux disease. Experimental stress enhances perception of reflux events in susceptible (anxious) individuals, but the relevance of stress experiments toward understanding potential effects of psychologic factors remains unknown.

TREATMENT

The therapeutic approach initially follows principles for treating gastroesophageal reflux disease under the assumption that pathologic reflux may have been overlooked in the evaluation and/or that symptoms may respond to antireflux treatment. Lifestyle modifications should be encouraged before relying solely on medications. Treatment with a proton pump inhibitor provides better symptom control than placebo, but the response is attenuated compared with that in conventional reflux disease. ${ }^{34}{ }^{35}$ Limited information suggests that heartburn also decreases with low-dose antidepressant therapy. ${ }^{27}$

\section{A5. Functional dysphagia \\ DEFINITION}

The diagnosis is restricted to patients with esophageal rather than oropharyngeal dysphagia, the hallmark symptom being a sensation of abnormal bolus transit through the esophageal body. Dysphagia is considered functional when there is no structural abnormality, pathological reflux, or pathology-based motility disturbance to explain the symptom.

\section{EPIDEMIOLOGY}

The epidemiology of functional dysphagia is poorly understood. Dysphagia is an uncommon principal symptom in the absence of structural abnormality or other esophageal explanation.

DIAGNOSTIC CRITERIA

At least 12 weeks, which need not be consecutive, in the preceding 12 months of:

(1) Sense of solid and/or liquid foods sticking, lodging, or passing abnormally through the esophagus; and

(2) Absence of pathologic gastroesophageal reflux, achalasia, or other motility disorder with a recognized pathologic basis.

\section{CLINICAL EVALUATION}

Careful exclusion of structural lesions is essential before assigning a functional diagnosis. Barium radiography using radio-opaque bolus challenge (e.g., barium pill or marshmallow) and fluoroscopy can help identify the anatomic level and nature of obstructing lesions. Endoscopy can importantly identify tumors, mucosal rings, strictures, and evidence of pathologic reflux. Negative evaluations should be followed by manometry. Dysphagia is the hallmark symptom of achalasia, a potential diagnosis even when other studies are unrevealing. Dysphagia associated with non-specific motility abnormalities (especially spastic disorders) may be more responsive than chest pain to interventions that affect motility, making manometry of greater utility in the management algorithms. ${ }^{21}$

\section{PHYSIOLOGIC FEATURES}

Patients with functional dysphagia have not been studied as well as patients with functional chest pain, but physiologic observations in the latter disorder are probably relevant to dysphagia. Both abnormal motor events and abnormal perception may contribute to symptom production. Limited data are available to support this hypothesis. Loss or reduction in the peristaltic response to swallowed food boluses may be relevant in some subjects. ${ }^{36}$

\section{PSYCHOLOGIC FEATURES}

Anecdotal information indicates that psychiatric diagnoses, especially anxiety, depression, and somatization disorders, are significantly more common in patients with functional dysphagia than in patients with other explanations for the symptom. ${ }^{1}$ Few substantial data are available for review.

TREATMENT

Treatment is initially directed at reassurance, avoidance of precipitating factors, and managing underlying motility abnormalities, if detected. Empirical trials of antireflux therapy are appropriate, even in the absence of pathologic reflux. Other treatments used in patients with functional chest pain of presumed esophageal origin can be tried, although efficacy is unproved. Excluding a mechanically obstructing process in the region of the lower esophageal sphincter (e.g., ring, stricture, motility abnormality) may require extra effort. 


\section{A6. Unspecified functional esophageal disorders \\ DEFINITION}

This diagnosis is reserved for poorly described esophageal complaints or symptoms that differ from the other functional disorders (e.g., gurgling, chest bloating). The diagnosis should not be used if principal symptoms meet criteria for another functional esophageal disorder. No data are available for epidemiology, diagnosis, physiologic and psychologic features, or management.

DIAGNOSTIC CRITERIA

At least 12 weeks, which need not be consecutive, in the preceding 12 months of:

(1) Unexplained symptoms attributed to the esophagus that do not fit into the previously described categories; and

(2) Absence of pathologic gastroesophageal reflux, achalasia, or other motility disorder with a recognized pathologic basis.

\section{Recommendations for future research}

Several underexplored areas in the functional esophageal disorders were identified:

- Further attention is needed toward defining the fundamental mechanisms of symptom production.

- Better treatment approaches are needed; both outcome and mechanism of effect should be studied, particularly for pharmacological and non-pharmacological treatments of identified psychosocial abnormalities.

- The effect of treatment interventions on health outcome in a broader sense than esophageal symptom reduction should be explored.

- Methods should be sought for improving accuracy of symptom-based criteria to reduce reliance on objective testing.

- The value of inclusive rather than restrictive criteria that encompass a broader definition within the esophagus and consider other gastrointestinal and non-gastrointestinal symptoms in presentation should be examined. The importance of the individual diagnoses (excepting rumination) over a combined "functional esophageal syndrome" should be evaluated critically.

1 Richter JE, Baldi F, Clouse R, et al. Functional esophageal disorders. In: Drossman DA, Richter JE, Talley NJ, et al, eds. The functional gastrointestinal disorders. Boston: Little, Brown, 1994:25-70.

2 Thompson WG, Heaton KW. Heartburn and globus in healthy people. Can Med Assoc f 1982;126:46-8.

3 Batch AJG. Globus pharyngeus [Part I]. I Laryngol Otolaryngol 1988;102:152-8.

4 Gray L. The relationship of the "inferior constrictor swallow" and "globus hystericus" or the hypopharyngeal syndrome. F Laryngol Otolaryngol 1983;97:607-18.

5 Wilson JA, Pryde A, Macintyre CCA, et al. Pharyngoesophageal dysmotility in globus sensation. Arch Otolaryngol Head Neck Sung 1989;115.1086-90.

6 Farkkila MA, Ertama L, Katila $\mathrm{H}$ et al. Globus pharyngis, commonly associated with esophageal motility disorders. Am $\mathcal{F}$ Gastroenterol 1994;89:503-8.

7 Deary IJ, S Scott, Wilson JA. Alexithymia and medically unexplained symptoms. F Personality Indiv Diff 1997;22 551-64.
8 Moser G, Wenzel-Abatzi TA, Stelzeneder M, et al. Globus sensation. Pharygoesophageal function, psychometric and
psychiatric findings, and follow-up in 88 patients. Arch psychiatric findings, and follow-
Intern Med 1998;158:1365-73.

9 Deary IJ, Wilson JA. Problems in treating globus pharyngis. Clin Otolaryngol 1994;19:55-60.

10 Sullivan PB. Gastrointestinal problems in the neurologically impaired child. Baillieres Clin Gastroenterol 1997;11:52946.

11 Malcolm A, Thumshirn MB, Camilleri M, et al. Rumination syndrome. Mayo Clin Proc 1997;72:646-52.

12 Amarnath RP, Abell RL, Malagelada JR. The rumination syndrome in adults. A characteristic manometric pattern. Ann Intern Med 1986:105:513-18.

13 O'Brien BD, Bruce BK, Camilleri M. The rumination syndrome. Clinical features rather than manometric diagnosis. Gastroenterology 1995;108:1024-9.

14 Einhorn AH. Rumination syndrome [merycism or merycasm]. In: Barnett HL, ed. Pediatrics. New York: AppletonCentury-Crofts; 1972:1576-8.

15 Whitehead WE, Schuster MM (eds). Rumination syndrome, vomiting, aerophagia, and belching. Gastrointestinal disorders: behavioral and physiological basis for treatment. Orlando, FL: Academic Press, 1985:67-90.

16 Soykan I, Chen J, Kendall BJ, et al. The rumination syndrome: clinical and manometric profile, therapy, and long-term outcome. Dig Dis Sci 1997;42:1866-72.

17 Kemp HG, Kronmal RA, Vlietstra RE, et al. Seven year survival of patients with normal or near normal coronary arteriograms. A CASS registry study. F Am Coll Cardiol 1986; 7: 479-83.

18 Frobert O, Funch-Jensen P, Jacobsen NO, et al. Upper endoscopy in patients with angina and normal coronary angiograms. Endoscopy 1995;27:365-70.

19 Fass R, Fennerty MB, Ofman JJ, et al. The clinical and economic value of a short course of omeprazole in patients with noncardiac chest pain. Gastroenterology 1998;115:429.

20 Shi G, Varannes SB, Scarpignato C, et al. Reflux related symptoms in patients with normal oesophageal exposure to acid. Gut 1995;37:457-64

21 Kahrilas PJ, Clouse RE, Hogan WJ. American Gastroenterological Association technical review on the clinical use of esophageal manometry. Gastroenterology 1994;107: of esophage 1865 .

22 Richter JE, Bradley LA, Castell DO. Esophageal chest pain: current controversies in pathogenesis, diagnosis and treatment. Ann Intern Med 1989;110:66-78.

23 Rao SSC, Gregersen H, Hayek B, et al. Unexplained chest pain: the hypersensitive, hyperactive, and poorly compliant esophagus. Ann Intern Med 1996;124:950-8.

24 Clouse RE, Carney RM. The psychologic profile of non-cardiac chest pain patients. Eur F Gastroenterol Hepatol 1995;7:1160-5.

25 Bradley LA, Scarinci IC, Richter JE. Pain threshold levels and coping strategies among patients who have chest pain and normal coronary arteries. Med Clinic North Am 1991;75:1189-202.

26 Achem SR, Kolts BE, MacMath T, et al. Effects of omeprazole versus placebo in treatment of noncardiac chest pain and gastroesophageal reflux disease. Dig Dis Sci 1997;42: 2138-45.

27 Clouse RE, Lustman PJ, Eckert TC, et al. Low-dose trazodone for symptomatic patients with esophageal contraction abnormalities: double-blind, placebo-controlled trial. Gastroenterology 1986;92:1027-36.

28 Cannon RO III, Quyyumi A, Mincemoyer R, et al. Imipramine in patients with chest pain despite normal coronary angiograms. N Engl f Med 1996;330:1411-17.

29 Klimes I, Mayou RA, Pearce MJ, et al. Psychological treatment of atypical non-cardiac chest pain: a controlled evaluation. Psychol Med 1990;20:605-11.

30 Talley NJ, Boyce P, Jones M. Identification of distinct upper and lower gastrointestinal symptom groupings in an urban population. Gut 1998;42:690-5.

31 Trimble KC, Pryde A, Heading RC. Lowered oesophageal sensory thresholds in patients with symptomatic but not excess gastroesophageal reflux. Evidence for a spectrum of visceral sensitivity in GORD. Gut 1995;37:7-12.

32 Baldi F, Ferrarini F, Longansei A. Acid gastroesophageal reflux and symptom occurrence. Analysis of some factors influencing their association. Dig Dis Sci 1989;34:1890-93.

33 Johnston BT, Lewis SA, Collins JSA, et al. Acid perception in gastro-oesophageal reflux disease is dependent on psychosocial factors. Scand f Gastroenterol 1995;30:1-5.

34 Lind T, Havelund T, Carlsson R, et al. Heartburn without oesophagitis. Efficacy of omeprazole therapy and features determining a therapeutic response. Scand $\mathcal{F}$ Gastroenterol 1997;32:974-9.

35 Watson RGP, Tham TCK, Johnston BT, et al. Double blind cross-over placebo controlled study of omeprazole in the treatment of patients with reflux symptoms and physiological levels of acid reflux - the "sensitive oesophagus." Gut 1997;40:587-90.

36 Howard PJ, Maher L, Pryde A, et al. Esophageal motor patterns during episodes of dysphagia for solids. $\mathcal{F}$ Gastointest Motil 1991;3:123-30. 